\title{
Проблема особенности смыслового выбора супруга женщиной на этапе создании семьи
}

\author{
Елена В. Плешакова \\ Донской государственный технический университет, г. Ростов-на-Дону, \\ Российская Федерация \\ E-mail: pleshakova_lenochka@mail.ru \\ ORCID ID: https://orcid.org/0000-0002-7102-8022
}

\begin{abstract}
Аннотация
Акт выбора будущего супруга особенно значим Аля женщины в силу того, что социокультурное «бремя» ошибки выбора брачного партнера Аля нее несравнимо выше, по сравнению с мужчиной. По предметному полю научного исследования, смысловой выбор особенно актуален Аля психологии. Во ВвеАении преАставлен анализ психологических исследований по проблеме смыслового выбора отечественных и зарубежных авторов. Он показал, что, в целом, все эти исслеАования феноменологичны, и исследований, ориентированных на результаты, имеющие, хотя бы отчасти, обобщенность (например, через математико-статистическое обобщение), нет. Это объясняется тем фактом, что смысловой выбор трактуется как уникальное явление, связанное с конкретным человеком, вне зависимости от понимания сути смыслового выбора - как ^ичностного, так и экзистенционального. Поэтому новизна нашего исслеАования состоит в отсутствии проведения ранее подобных исследований, в которых предметом выступал бы смысловой выбор женщиной супруга на этапе созАания семьи. В теоретическом обосновании преАставлены причины отсутствия еАиного поАхоАа к пониманию сути смыслового выбора. По мнению авторов, он отсутствует из-за трудностей при проверке теоретических положений, отличий направлений в изучении смыслового выбора по специорике преАметного поля исслеАований, а также из-за отсутствия еАиного поАхола в понимании Аинамики самого смыслообразования. В разАеле «ОбсужАение результатов» авторы опреАеляют компоненты, интеграция которых необхоАима А^я того, чтобы определить понятие «смысловой выбор супруга женщиной на этапе создании семьи», улеляя внимание, в том числе, ценностям. Раздел «Заключение» содержит обобщенные результаты анализа, провелённого авторами и намеченные авторами тенденции в исследовании проблемы смыслового выбора.
\end{abstract}

\section{КАючевые слова}

семья, выбор супруга, смысл, ценности, структура, порядок в структуре, гиперболическое распрелеление 
СОЩИАЯЬНАЯ ПСИХОЯОГИЯ

\title{
Для цитирования
}

Плешакова Е.В. Проблема особенности смыслового выбора супруга женщиной на этапе создании семьи // Инновационная наука: психология, педагогика, дефектоиогия. 2021. Т. 4, № 5. С. 79-86. doi: https://doi.org/10.23947/2658-7165-2021-4-5-79-86

\section{The problem of the peculiarity of the meaning choice of a spouse by a woman at the stage of creating a family}

\author{
Elena V. Pleshakova \\ Don State Technical University, Rostov-on-Don, Russian Federation \\ E-mail: pleshakova_lenochka@mail.ru \\ ORCID ID: https://orcid.org/0000-0002-7102-8022
}

\begin{abstract}
The act of choosing a future spouse is especially significant for a woman. This is due to the fact that the sociocultural "burden" of the mistake of choosing a marriage partner is incomparably higher for woman than for a man. In the subject field of scientific research, a meaning choice is especially relevant for psychology. The Introduction presents an analysis of psychological research on the problem of meaning choice by Russian and foreign authors. The analysis showed that, in general, all these studies are phenomenological, and there are no results-oriented studies that at least in part have generalization (for example, mathematical and statistical). This is explained by the fact that the semantic choice is interpreted as a unique phenomenon associated with a particular person, regardless of understanding the essence of the meaning choice - both personal and existential. Therefore, the novelty of our study lies in the absence of earlier similar studies, in which the subject would be the semantic choice of a spouse by a woman at the stage of creating a family. The Theoretical support presents the reasons for the lack of a unified approach to understanding the essence of meaning choice. According to the authors, it is absent due to difficulties in verifying theoretical positions, differences in directions in the study of meaning choice in terms of the specifics of the subject field of research, and also due to the lack of a unified approach to understanding the dynamics of the formation of meaning itself. In the "Discussion of the results" section, the authors define the components, the integration of which is necessary in order to define the concept of "the meaning choice of a spouse by a woman at the stage of creating a family", paying attention, among other things, to values. The section "Conclusion" contains the generalized results of the analysis carried out by the authors and the trends outlined by the authors in the study of the problem of the meaning choice.
\end{abstract}




\section{Keywords}

family, choice of spouse, meaning, values, structure, order in the structure, hyperbolic distribution

\section{For citation}

Pleshakova E.V. (2021). The problem of the peculiarity of the meaning choice of a spouse by a woman at the stage of creating a family. Innovative Science: psychology, pedagogy, defectology, 4(5), 79-86. doi: https://doi.org/10.23947/2658-7165-2021-4-5-79-86

\section{Введение}

Эффективность функционирования такого социального института, как семья, имеет колоссальное значение для эффективности функционирования любого общества. Вследствие, научное изучение причин, условий, факторов, механизмов и динамики функционирования семьи актуально для многих научных дисциплин и должно носить междисциплинарный характер, где свое достойное место должна занять психология. В динамике развития семьи выделяются этапы, которые включены в общий процесс и определяют его функционирование, но, тем не менее, имеют относительно самостоятельный статус. Акт выбора будущего супруга, несомненно, можно отнести к таким этапам.

Психологических исследований, в которых смысловой выбор супруга выступал бы предметом отдельного исследования, не проводилось, хотя раздичные аспекты выбора будущего супруга (супруги) как в зарубежной, так и в отечественной психологии, изучадись. В зарубежной психологии - это исследования мотивационного выбора в психоанадизе (Winch, 1955), когнитивной психологии (Murstein, 1970; Centers, 1975), гуманистической психологии (Peter, Landy, 1991). Также, в зарубежных исследованиях изучается вдияние внешних факторов на выбор супруга, таких как, например, наличие несемейного опыта (Ghimire, Axinn, Yabiku, Thornton, 2006; Cazes, 2006).

В отечественной психологии работ такого плана относительно меньше (Айгумова, Айгунов, 2010). Анализ отечественных работ показал, что в них обнаруживается два наиболее «негативных» момента. Во-первых, относительно низкая «проработанность» всех исследований в метододогически-понятийном плане: 1) понятия «мотив выбора», «мотивация выбора», «мотивационная сфера выбора» используются вне понятийного контекста понятия «мотив», «мотивация», «мотивационная сфера»; 2) словосочетание «смысловой выбор» используется в работе в «литературном» контексте, нежели имеет научный статус (Айгумова, Айгунов, 2010). Во-вторых, эмпирические результаты отличаются низкой валидностью в силу того, что слабо инструментально «обеспечены». 
СОЦИАЛЬНАЯ ПСИХОЛОГИЯ

\section{Теоретическое обоснование}

Сегодня в психодогии нет однозначного определения понятия «смысловой выбор» в силу того, что нет единого подхода к пониманию сути такого выбора. Причин тому несколько и, как нам представляется, среди основных можно назвать следующие:

1) так как смысловой выбор - это один из актов смыслообразования (смыслопроявления) (Абакумова, 2003), то должен быть единый подход в понимании динамики самого смыслообразования, а сегодня в метододогии изучения смыслов (Деонтьев, 2007) существуют два связанных, но не дополняющих друг друга, подхода в понимании «динамики смысловых образований»: «бодьшая», связанная с жизнедеятельностью человека в целом, и «малая», связанная с его конкретной деятельностью,

2) в силу сложности и многомерности объекта исследования (смысловой сферы человека), в психологии существует несколько направлений в изучении смыслового выбора, которые, «пересекаясь» в некоторых аспектах метододогии (системность, трансперсональность, уникальность и т. д.), в то же время, отличаются друг от друга по специфике предметного поля исследований, что проявляется не только в определении понятия «смысловой выбор», но и понимании механизмов ее становления. И. В. Абакумова делает акцент на генетических аспектах такого выбора (Абакумова, Годунов, Гурцкой, 2019), Д. А. Леонтьев делает акцент на основных критериях смыслового выбора (Деонтьев, Пилипко, 1995), Е. В. Клочко делает акцент на многомерности и многоуровневости структуры смыслового выбора (Клочко, Галажинский, 2009).

3) теоретические положения очень трудно проверить на эмпирическом уровне, так как все психологические работы в этой области отличаются феноменологичностью, что объясняется тем фактом, что смысловой выбор трактуется как явление уникальное, индивидуальное, связанное с конкретным человеком.

\section{Обсуждение резудьтатов}

В такой ситуации для изучения этого феномена логично обратиться к более обобщенному понятию «смысловой выбор». Но мы сталкиваемся с тем фактом, что существует несколько концепций, отражающих те или иные аспекты этого феномена.

Взятые в отдельности, и условия смыслового выбора, и его механизмы, не позволяют определить суть понятия «смысловой выбор супруга женщиной на этапе создании семьи». Но и просто их элементарный набор так же не отражает сущность этого феномена.

Например. Можно ли условие «высокая значимость выбора для дичности» считать достаточным для определения понятия. Мы считаем, что нет, учитывая современный социокультурный контекст (отношение к разводу). У Д. А. Аеонтьева 
понятие «альтернатива» лежит в «базисе» смыслового, хотя многие словари уже на постоянной основе включают слово «выбор» в определение понятия «альтернатива» (Деонтьев, 2007).

Мы посчитади, что для того, чтобы определить понятие «смысловой выбор супруга женщиной на этапе создании семьи», необходимо добавление чего-то значимого для интегрирования всего того, что было названо выше. Косвенно, направление дальнейшего анализа задаются в концепции смыслового выбора И. В. Абакумовой (выделяется роль неповторимого опыта, эмоционадьных предпочтений, когнитивных стилей мышления) и Д. А. Аеонтьева (интересы, убеждения, установки) (Деонтьев, 2007).

В рамках такой «подсказки» и на основе анализа литературы, мы считаем, нужно обратиться к ценностям - ценностям семьи, определяемым функциями современной семьи. Отметим, что смысловой выбор супруга на этапе создания семьи нужно изучать в связи с индивидуадьной системой семейных ценностей женщины, совершающей выбор. Индивидуальная система ценностей здесь представдяет собой совокупность иичностных ценностей, которые в рамках семьи пересекаются в пространстве общечеловеческих ценностей относительно функций семьи, ее целей, задач и содержания ее существования. Ярким примером влияния ценностей на смысловой выбор супруга является принятие или отвержение возможности межкультурного брака (Алагуев, 2021).

Эти ценности образуют систему, структура которой характеризуется порядком, который и будет проявдяться в смысловом выборе супруга. Мера такого порядка определяется соотношением между количественной выраженностью слабо функционально зависимых семейных ценностей у женщины в их совокупной значимости, которая ограничивается особенностями дичности женщины и ситуацией вступления в брак (объективная возможность выбора, экономический и социальный статус, возраст женщины и т. д.). Так, например, исследователи гендерного аспекта выбора супруга выявиди, что ддя женщин Индонезии как принадлежность к семейному классу, так и образование очень важны при выборе мужа (Malhotra, 1991).

Изучать количественно-структурную организацию слабо функционально зависимых семейных ценностей у женщины в ситуации вступления в брак можно в соответствии с моделью количественного подхода к изучению структуры психологических феноменов, предложенную В. А. Дорофеевым (Дорофеев, 2019). Мера совокупной значимости слабо функционально зависимых семейных ценностей у женщины ограничивается особенностями дичности женщины и ситуацией вступления в брак (объективная возможность выбора, экономический и социальный статус, возраст женщины и т. д.). Структурная организация семейных ценностей имеет свою меру, определяемую соотношением между количественной выраженностью слабо функционально зависимых семейных 
СОЦИАЛЬНАЯ ПСИХОЛОГИЯ

ценностей у женщины. Математически мера структурности отражена в ранговом по параметру гиперболическом Н-распределении. Параметры этого распределения имеют общесистемную интерпретацию и, таким образом, могут быть интерпретированы применительно смысловому выбору супруга женщиной на этапе создания семьи.

\section{Закдючение}

Проведенный анализ имеющихся концептуальных моделей психологической сути «смыслового выбора» и формально - содержательные аспекты специфики смыслового выбора будущего супруга, позволил нам ввести рабочее понятие «смысловой выбор супруга женщиной на этапе создания семьи» и дать ему такое определение «Смысловой выбор супруга женщиной на этапе создания семьи - это выбор, осуществленный женщиной одной альтернативы из всей совокупности возможных на основе порядка в структуре ее семейных ценностей и в условиях относительно высокой значимости этого выбора».

Конечно, предложенная модель формадизации в изучении смыслового выбора супруга женщиной на этапе создания семьи потребует доработки. Потребуется существенная эмпирическая проверка выдвинутых предположений с последующей коррекцией, в том числе, и теоретических положений. Трудности возникнут при эмпирическом изучении смыслов в силу их онтологического статуса, в определении соразмерности в выраженности семейных ценностей у женщины. Тем не менее, как нам представдяется, перспективы имеются и их необходимо реализовывать.

Автор заявляет об отсутствии конфликта интересов.

\section{Дитература}

Абакумова, И. В. (2003). Смыслообразование в учебном процессе. (Диссертация). Ростов-на-Дону: Ростовский государственный университет.

Абакумова, И. В., Годунов, М. В., Гурцкой, Д. А. (2019). Смысловой выбор как психологическая проблема. Вестник Удмуртского университета. Серия: Философия. Психология. Педагогика, 29(4), 413-420.

Айгумова, 3. И., Айгунов, В. Р. (2010). Мотивацุия выбора супруга: Монография. М.: «Прометей» МПГУ.

Алагуев, М. В. (2021). Вступление в межкультурный брак: факторы выбора брачного партнера. Национальный психологический журнал, 1(41), 63-75.

Дорофеев, В. А. (2019). Системный взгляд на проблему доверия руководителю в организации. Азимут научных исследований: педагогика и психология, 8-1(26), 113-117.

Клочко, Е. В., Галажинский, Э. В. (2009). Психология инновацуионного поведения. Томск: ТГУ. 
Деонтьев, Д. А. (2007). Психология смысла: природа, строение и динамика смысловой реальности. 3-е изд. доп. М.: Смысл.

Деонтьев, Д. А., Пилипко, Н. В. (1995). Выбор как деятельность: дичностные детерминанты и возможности формирования. Вопросы психологии, 1, 97-111.

Cazes, M.-H. (2006). An Example of Demographic Anthropology, the Study of Matrimonial Exchanges - Endogamy, Choice of Spouse and Preferential Marriage. Collegium Antropologicum, 30(3), 475-478.

Centers, R. (1975). Sexual Attraction and Love: An Instrumental Theory. (Illinois: Charles C. Thomas Publisher).

Ghimire, D. J., Axinn, W. G., Yabiku, S. T., Thornton, A. (2006). Social Change, Premarital Nonfamily Experience, and Spouse Choice in an Arranged Marriage Society. American Journal of Sociology, 111(4), 1181-1218.

Malhotra, A. (1991). Gender and changing generational relations: Spouse choice in Indonesia. Demography, 28(4), 549-570. doi: https://doi.org/10.2307/2061422

Murstein, B. I. (1970). Stimulus. Value. Role: A Theory of Marital Choice. Journal of Marriage and Family, 32(3), 465-481. doi: https://doi.org/10.2307/350113

Peter, M., Landy, L. (1991). Divorce and the Wheel Theory of Love. Journal of Divorce $\mathcal{E}$ Remarriage, 15(1-2), 3-22. doi: https://doi.org/10.1300/J087v15n01_02

Winch, R. F. (1955). The theory of complementary needs in mate selection. American Sociological Review, 20, 552-555. doi: https://doi.org/10.2307/2092563

\section{References}

Abakumova, I. V. (2003). Meaning formation in the educational process. (Dissertation). Rostov-on-Don: Rostov State University. (in Russ.).

Abakumova, I. V., Godunov, M. V., Gurtskoy, D. A. (2019). Meaning choice as a psychological problem. Vestnik of the Udmurt University. Series: Philosophy. Psychology. Pedagogy, 29(4), 413-420. (in Russ.).

Aigumova, Z. I., Aigunov, V. R. (2010). Motivation for Choosing a Spouse: a Monograph. Moscow: "Prometheus" Moscow Pedagogical State University. (in Russ.).

Alaguev, M. V. (2021). Entering into an intercultural marriage: factors in choosing a marriage partner. National Psychological Journal, 1(41), 63-75. (in Russ.).

Dorofeev, V. A. (2019). A systematic view of the problem of trust in a leader in an organization. Research Azimuth: Pedagogy and Psychology, 8-1(26), 113-117. (in Russ.).

Cazes, M.-H. (2006). An Example of Demographic Anthropology, the Study of Matrimonial Exchanges - Endogamy, Choice of Spouse and Preferential Marriage. Collegium Antropologicum, 30(3), 475-478.

Centers, R. (1975). Sexual Attraction and Love: An Instrumental Theory. (Illinois: Charles C. Thomas Publisher).

Ghimire, D. J., Axinn, W. G., Yabiku, S. T., Thornton, A. (2006). Social Change, Premarital Nonfamily Experience, and Spouse Choice in an Arranged Marriage 
СОЦИАЯЬНАЯ ПСИХОЯОГИЯ

Society. American Journal of Sociology, 111(4), 1181-1218.

Klochko, E. V., Galazhinsky, E. V. (2009). Psychology of innovative behavior. Tomsk: Tomsk State University. (in Russ.).

Leontiev, D. A. (2007). Psychology of meaning: nature, structure and dynamics of meaning reality. 3rd ed. add. Moscow: Smysl. (in Russ.).

Leontiev, D. A., Pilipko, N. V. (1995). Choice as an Activity: Personal Determinants and Possibilities of Formation. Questions of psychology, 1, 97-111. (in Russ.).

Malhotra, A. (1991). Gender and changing generational relations: Spouse choice in Indonesia. Demography, 28(4), 549-570. doi: https://doi.org/10.2307/2061422

Murstein, B. I. (1970). Stimulus. Value. Role: A Theory of Marital Choice. Journal of Marriage and Family, 32(3), 465-481. doi: https://doi.org/10.2307/350113

Peter, M., Landy, L. (1991). Divorce and the Wheel Theory of Love. Journal of Divorce \& Remarriage, 15(1-2), 3-22. doi: https://doi.org/10.1300/J087v15n01_02

Winch, R. F. (1955). The theory of complementary needs in mate selection. American Sociological Review, 20, 552-555. doi: https://doi.org/10.2307/2092563 